\section{A preventable teratology: isotretinoin}

It was concerning to read Henry and colleagues' study on the poor adherence to pregnancy prevention while women are taking isotretinoin. ${ }^{1}$

This drug was first licensed in 1982 in the United States, and the first reports on concerns about birth defects occurred within a year. Recommendations from the Teratology Society were first published in 1991. ${ }^{2}$

The reported risk for isotretinoin embryopathy is $35 \%$ for an embryo or fetus that is exposed beyond the 15th day after conception. ${ }^{3}$ The evidence supports the exposure to the embryo or fetus as the risk, not the use of the medication before conception. The embryopathy is well described, with craniofacial, cardiovascular and central nervous system (CNS) "disruptive" anomaly patterns.

Subnormal intelligence was also reported in a prospectively collected cohort of 31 five-year-old children exposed prenatally, with $19 \%$ having a full-scale intelligence quotient (IQ) less than 70 and $28 \%$ having an IQ in the 71-85 range. ${ }^{4}$ The intellectual deficit was not always associated with the finding of other non-CNS major disruptive anomalies: 6 of 10 children with borderline IQ had no identified major anomalies (all the children with severe IQ deficit had other identified major anomalies).

This evidence point is important for the clinical use of ultrasound screening of the exposed embryo or fetus for congenital anomalies and having the conclusion of "no anomalies, therefore not affected."

Henry and colleagues' results indicate that a much stronger warning and more counselling are likely required to prevent pregnancy. The teratology messaging needs to start first with the prescribing physician and informed consent from the patient. However, there needs to be stronger oversight from industry and the dispensing pharmacist (who should ask, "What birth control method will you be using while you are taking this medication?").

Improved knowledge translation about teratology and changes to the pre- scribing process clearly fit into the Choosing Wisely theme. This type of exposure to the embryo or fetus is entirely preventable. Isotretinoin embryopathy is not an acceptable pregnancy outcome, even when one considers patients' autonomy and their choice of method for preventing pregnancy.

\section{R. Douglas Wilson MD}

Cumming School of Medicine, University of Calgary, Calgary, Alta.

\section{References}

1. Henry D, Dormuth C, Winquist B, et al. Occurrence of pregnancy and pregnancy outcomes during isotretinoin therapy. CMAJ 2016;188:723-30.

2. Recommendations for isotretinoin use in women of childbearing potential. Teratology 1991;44:1-6.

3. Retinoic acid embryopathy. In: Jones KL, Jones MC, del Campo M. Smith's recognizable patterns of human malformation, 7th ed. Philadelphia: Elsevier; 2013:742-3.

4. Lammer EJ, Hayes AM, Schunior A, et al. Risk for major malformations among human fetuses exposed to isoretinoin (13-cis-retinoic acid). Teratology 1987;35:68.

CMAJ 2016. DOI:10.1503/cmaj.1150114

\section{Canada's immigration policy toward black people}

McKinnon and colleagues deserve a great deal of credit in authoring one of the few articles that address black-white racial disparities in preterm birth in Canada. ${ }^{1}$ Despite the absolute disparities being smaller after adjusting for other variables, the relative risk ratios were very similar, as were the risk differences, between black Canadians and black Americans. These findings go against the authors' hypothesis that there would be lower preterm rates in Canada than in the United
States, because of Canada's better history with black people and its universal health care system. However, McKinnon and colleagues may not have been aware that Canada has an exclusionary history toward black people and is perhaps not as egalitarian as they believed. In fact, before the civil rights movements of the 1960s, Canada's immigration policy could be described as racist. ${ }^{2}$ To illustrate this troubling part of Canada's past is a statement from the 1958 director of the immigration branch of the Department of Citizenship and Immigration in 1958: ${ }^{2}$

It is not by accident that coloured British subjects other than negligible numbers from United Kingdom are excluded from Canada. ... They do not assimilate readily and pretty much vegetate to a low standard of living. Despite what has been said to the contrary, many cannot adapt themselves to our climatic conditions.

McKinnon and colleagues' hypothesis on racial history in Canada may be misinformed. However, their article is definitely a step in the right direction toward improving equality, because it shows inequality in the beginnings of life.

\section{Myles C. Snooks BSc(Hon)}

Memorial University of Newfoundland, St. John's, NFLD

\section{References}

1. McKinnon B, Yang S, Kramer MS, Bushnik T, Sheppard AJ, Kaufman JS, Comparison of blackwhite disparities in preterm birth between Canada and the United States. CMAJ 2016;188:E19-E26.

2. Satzewich V. Racism and Canadian immigration policy: the government's view of Caribbean migration, 1962-1966. Can Ethnic Stud 1989; 21:77-97.

CMAJ 2016. DOI:10.1503/cmaj.1150115

\title{
Naturopathic medicine for preventing cardiovascular disease
}

A digit was dropped inadvertently from the Clinical Trials identifier number in the abstract of the article by Seely and colleagues. ${ }^{1}$ The correct number is NCT00718796. CMAJ apologizes for the error.

\section{Reference}

1. Seely D, Szczurko O, Cooley K, et al. Naturopathic medicine for the prevention of cardiovascular disease: a randomized clinical trial. CMAJ 2013;185:E409-16.

CMAJ 2016. DOI:10.1503/cmaj.1150116 